\title{
Disability in children and adolescents must be integrated into the global health agenda
}

\author{
Alarcos Cieza and colleagues argue that services for children and young people with disability
}

need greater priority

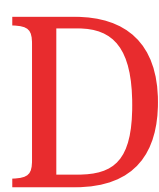

isability has low priority in the general agenda of child and adolescent health. Although one billion people have some form of disability, people with disability are among the world's most marginalised and discriminated against groups. Driven by global goals, most countries have focused primarily on reducing childhood mortality, leaving disability low in their priorities. ${ }^{1}$ Few countries provide adequate quality services. There are at least three good reasons why countries urgently need to tackle this.

Firstly, the number of people living with disability is set to increase dramatically because of epidemiological and demographic trends, such as the relatively young populations of low income countries. ${ }^{2-4}$ These trends are usually considered in terms of increasing disability among older people with chronic conditions, ${ }^{5-8}$ rather than among children. ${ }^{9}{ }^{10}$ With child survival increasing but not all children who survive being able to thrive, more children will need health services to optimise their developmental outcomes. However, most health systems lack capacity to deal with current needs of children with disability, let alone meet the rising demand.

\section{REY MESSAGES}

- Disability has low priority within global child and adolescent health agendas

- The unmet needs of children and adolescents with disability are steadily increasing because services have not been expanded despite many more children requiring care

- Services that do exist are invariably of poor quality or under-resourced.

- Services for children with disability in primary healthcare must be scaled up, and rehabilitation services for those in need should be integrated within health systems
Secondly, children with disability often need specific rehabilitation services related to their impairment or disability. Rehabilitation interventions-which can tackle impairments, functioning limitations, and restrictions such as mobility, vision, and cognition-can have a profound impact on functioning and wellbeing. Rehabilitation is often required for considerable periods of time. The limited evidence available shows major gaps and unmet needs for such services, particularly in low income countries. ${ }^{11} 12$

Lastly, access to appropriate care is a fundamental human right. Children with disability repeatedly face barriers to care, including physical ones, ${ }^{13}$ causing much suffering, hardship, and isolation. But the greatest obstacles they encounter are negative or ill informed attitudes. ${ }^{14}$ Without a shift in attitudes, it is likely that they will continue to be denied access to care by health providers.

\section{Growing numbers of children with disability}

The low priority accorded to disability is reflected in the lack of data. One recent global analysis estimated that 291 million children and adolescents experience disability due to epilepsy, intellectual disabilities, or sensory impairments. ${ }^{15}$ But the real impact of childhood disability is not known yet.

Epidemiological evidence so far has been fragmented, limited to prevalence data for specific health conditions. The only source of global evidence, the World Report on Disability, found that about $5 \%$ of children experience disability, but the report relied on data from $2004 .{ }^{4}$ A comprehensive perspective is vital: it should consider a broad list of chronic health conditions with high levels of associated disability that profoundly affect children's functioning and wellbeing. This will enable appropriate provision of health services.

We explored trends in prevalence and associated disability of a number of common non-communicable diseases and injuries using the Global Burden of Disease as a data source, comparing data from 1990 to $2019 .{ }^{16}$ Since the list of conditions can be broad, we adopted an approach that limited the number of conditions but was still representative without being exhaustive. We selected the 20 impairments and health conditions with the highest number of years lived with disability, which reflected the level of disability according to Global Burden of Disease data. Infectious diseases, such as malaria, and conditions driven by prevalence rather than disability, such as micronutrient deficiencies, were excluded. In addition, we convened a group of experts in disability to discuss the list and add any conditions or impairments associated with high levels of disability and needing health services. The final list comprised 14 health conditions or impairments, including two large groups of injuries and congenital anomalies.

Results show that for most of the conditions the estimated global prevalence remained virtually unchanged during this period (table 1), but the numbers of children and adolescents living with disability rose substantially owing to population increases. Conditions that exceeded 100 million cases among those aged $<20$ years include: migraine (196.0 million), injuries (154.7 million), asthma (100.3 million), and hearing impairment (102.3 million). The greatest increase was in migraine (from 159.5 million in 1990 to almost 200 million in 2019). Table 1 shows that the number of years lived with disability for all conditions has also increased substantially since 1990 . Full data are available on bmj.com.

These numbers are set to escalate with demographic trends: in low income countries, particularly in sub-Saharan Africa, children under 14 years typically constitute more than $40 \%$ of the total population. ${ }^{17}$ Already, there are nearly 500 million more children and adolescents today than in 1980.

\section{Health systems lack capacity to tackle needs}

Despite the numbers needing care, services for children and adolescents with disability are woefully inadequate. Health systems 


\begin{tabular}{|c|c|c|c|c|c|c|}
\hline Long term impairment/chronic condition & 1990 & 2019 & 1990 & 2019 & 1990 & 2019 \\
\hline Hearing impairment & 4.3 & 4.4 & 90.9 & 102.3 & 3.3 & 3.5 \\
\hline Vision impairment & 1.4 & 1.4 & 29.5 & 32.6 & 1.5 & 1.6 \\
\hline Congenital anomalies* & 1.3 & 1.2 & 28.2 & 29.1 & 3.3 & 3.4 \\
\hline Conduct disorder & 1.5 & 1.7 & 32.7 & 40.1 & 4.0 & 4.9 \\
\hline Dermatitis & 4.3 & 4.2 & 90.4 & 98.3 & 3.8 & 4.1 \\
\hline Anxiety & 2.4 & 2.5 & 50.0 & 57.6 & 5.0 & 5.7 \\
\hline Injuriest & 7.5 & 6.6 & 158.1 & 154.7 & 5.7 & 5.0 \\
\hline Asthma & 4.4 & 4.3 & 93.1 & 100.3 & 3.7 & 4.0 \\
\hline Depression & 0.9 & 1.0 & 18.6 & 23.4 & 3.5 & 4.4 \\
\hline
\end{tabular}

simply lack the capacity to meet demand. Even without available global estimates on unmet needs of children with disability, evidence consistently shows the many barriers to care they face.

Two conventions ratified by most countries-the Convention on the Rights of the Child ${ }^{18}$ and the Convention on the Rights of Persons with Disabilities ${ }^{19}-$ provide for all children to be entitled to care. Yet in reality, even basic healthcare needs of children with disability are often not met, with a lack of access to primary care or community services. ${ }^{1120-22}$

The rehabilitation services needed to optimise functioning often do not exist or are underdeveloped or underresourced. ${ }^{11}$ And when available, services are often costly, not physically inclusive, or accessible only in urban areas. ${ }^{23-25}$ The end result is poor quality of services-an issue often raised by children with disability and their caregivers. ${ }^{2627}$ An example from India shows underutilisation of rural rehabilitation services because of poor acceptability. $^{28}$

Children with disability often need particular therapies, assistive technology, or environments to be adapted for them. In many countries, only $5-15 \%$ of people who need assistive technology are able to get it, and children are even less likely to receive it than adults. ${ }^{29}$ For example, in Malawi, only $5 \%$ of children with disability attending rehabilitative services receive rehabilitative equipment. ${ }^{20}$ Limited resources are a key barrier, but the invisibility of children with disability is the root problem of many deficiencies. A lack of evidence and data hinders policy making. ${ }^{30}$ Another critical issue is the lack of qualified healthcare professionals and medical equipment to tackle specific needs. For example, in Ethiopia, many children with autism and intellectual disability do not receive the care they need because of the lack of training and knowledge of healthcare professionals and the absence of referral mechanisms. ${ }^{31}$

A 2017 WHO paper noted that the current workforce of skilled rehabilitation professionals in most countries was totally inadequate to serve population needs, with the numbers of occupational therapists, physiotherapists, physical medicine and rehabilitation doctors, speech and language therapists, prosthetists, and orthotists often just one tenth of that required. $^{32}$

In addition, rehabilitation services are often not integrated within health systems and thus lack the necessary quality and accountability mechanisms. Sometimes such services are provided by non-governmental organisations, where monitoring mechanisms may be insufficient. Other factors that also have a role include access barriers, high out-ofpocket expenses, long waiting times, and a lack of awareness about what rehabilitation entails. ${ }^{33}$

For children with disability, negative or ill informed attitudes are a major obstacle. Studies have shown that in some countries one of the main barriers to access to care has been discrimination, including from health providers. Evidence of the low priority given to children with disability can be seen in the fallout from the covid19 pandemic. An ongoing Human Rights
Watch survey with respondents from 54 countries found children with disability among the hardest hit, as services for them often fall by the wayside. ${ }^{34}$

\section{The way forward}

Disability urgently needs far higher priority in the child and adolescent health agendas. Low and middle income countries especially need to tackle the huge unmet need for services, which will only escalate with demographic changes. While services need to be built up, a lack of interventions is not the inherent issue. Numerous effective options for children with disability currently exist (see supplementary file 2), but they are not made available in most countries. For example, a recent analysis on hearing aids found that only $17 \%$ of the 400 million people "in need" of hearing aids have one. ${ }^{35}$ To move forward we need a shift of attitudes and the commitment of all relevant parties in the disability and health sectors.

Governments need to scale up service delivery with a strong focus on primary healthcare. This will help widen access and meet rising demand from the growing number of children with disability, many of whom will require services close to home. Primary care can become an essential platform and starting point for the care needed beyond and above the health sector. Some children might otherwise never receive the care they need.

Also, rehabilitation services need to be expanded to reach all children in need. This can happen only through integration into the health system and specifically at the primary care level. Providing early access to 
rehabilitation services is crucial to ensure optimal outcomes and mitigate the risks of ongoing complications that may affect health and overburden health systems. ${ }^{36}$

Evidence shows that early intervention at the primary care level can significantly reduce the prevalence of many chronic conditions and delay the onset of conditions, such as for cerebral palsy. ${ }^{37-39}$ Timely prevention interventions that target risk factors can also prevent conditions associated with high levels of disability. Stepping up rehabilitation services will entail sensitising and training the health workforce, who need the necessary information and skills to provide specific services. In addition, families can be given support and education, including on stigma and discrimination, which are at the root of many barriers.

Governments need to look at children with disability with fresh eyes and bring them out of their invisibility to inclusion. Countries need to commit to prioritising children who are among the most disadvantaged in many societies.

Contributors and sources: $\mathrm{AC}$ is a psychologist and public health professional currently heading the sensory functions, disability, and rehabilitation unit at WHO. KK has a background in mental health and currently works as a technical officer in the disability programme of WHO. MGS is a physical therapist with a long clinical, research, and teaching practice in the field of rehabilitation, currently working as a lecturer and researcher in physical therapy at the University of Murcia. SC is a medical doctor with expertise in data, analytics, and designing and implementing health and disability surveys, and is currently the director of the data and analytics department at WHO. MB is a communications consultant and public health specialist with extensive experience in news media and working for health agencies, currently consulting for $\mathrm{WHO}$. OL is a neonatologist, paediatrician, and public health expert with long global and country experience and expertise in maternal and child health, currently working for the WHO newborn health programme. CS is a child neuropsychiatrist and public health expert, and focal point for child and adolescent mental and brain health in the department of mental health and substance use at WHO. RB is a medical doctor with an expertise on health policy and financing; he leads disability, NCDs, and child injury prevention at the health section at Unicef. DR is a medically trained epidemiologist working on adolescent health research, with a focus on low and middle income countries, currently working as a medical officer for the adolescent and young adult health programme of WHO. AC, SC, and DR conceptualised the manuscript. $\mathrm{AC}$ is the guarantor. $A C, K K, M B$, and MGS wrote the manuscript. KK and MGS undertook the statistical analyses. SC, OL, CS, $\mathrm{RB}, \mathrm{DR}$, and $\mathrm{MB}$ reviewed, commented on, and revised the manuscript. The views expressed in this article do not necessarily represent the views, decisions, or policies of the institutions with which the authors are affiliated.

Competing interests: We have read and understood BMJ policy on declaration of interests and have no relevant interests to declare.
Provenance and peer review: Commissioned; externally peer reviewed.

This article is part of a series proposed by WHO and Unicef and commissioned by The BMJ, which peer reviewed, edited, and made the decision to publish. Open access fees are funded by WHO and Unicef.

Alarcos Cieza, unit head ${ }^{1}$

Kaloyan Kamenov, technical officer ${ }^{1}$

Mariano Gacto Sanchez, lecturer and researcher ${ }^{2}$ Somnath Chatterji, department director ${ }^{3}$

Mangai Balasegaram, public health specialist ${ }^{4}$

Ornella Lincetto, medical officer ${ }^{5}$

Chiara Servili, technical officer ${ }^{6}$

Raoul Bermejo, coordinator ${ }^{7}$

David A Ross, medical officer ${ }^{8}$

${ }^{1}$ World Health Organization, Sensory Functions, Disability and Rehabilitation, Geneva, Switzerland

${ }^{2}$ EUSES, University of Girona, Girona, Spain

${ }^{3}$ World Health Organization, Data and Analytics Department, Geneva, Switzerland

${ }^{4}$ Munich, Germany

${ }^{5}$ World Health Organization, Newborn Health, Geneva, Switzerland

${ }^{6}$ World Health Organization, Brain Health, Geneva, Switzerland

${ }^{7}$ Unicef, Programme Division, Health Section, New York, USA

${ }^{8}$ World Health Organization, Adolescent and Young Adult Health, Geneva, Switzerland

Correspondence to: A Cieza

ciezaa@who.int

\section{Check for updates}

This is an Open Access article distributed under the terms of the Creative Commons Attribution IGO License (https://creativecommons.org/licenses/ by-nc/3.0/igo/), which permits use, distribution, and reproduction for non-commercial purposes in any medium, provided the original work is properly cited.

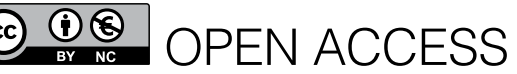

1 Alkema L, Chou D, Hogan D, et al. United Nations Maternal Mortality Estimation Inter-Agency Group collaborators and technical advisory group. Global, regional, and national levels and trends in materna mortality between 1990 and 2015, with scenariobased projections to 2030: a systematic analysis by the UN Maternal Mortality Estimation Inter-Agency Group. Lancet 2016;387:462-74. doi:10.1016/ S0140-6736(15)00838-7

2 Halfon N, Houtrow A, Larson K, Newacheck PW. The changing landscape of disability in childhood. Future Child 2012;22:13-42. doi:10.1353/foc.2012.0004

3 Newacheck PW, Halfon N. Prevalence and impact of disabling chronic conditions in childhood. Am J Public Health 1998;88:610-7. doi:10.2105/ AJPH.88.4.610

4 World Health Organization. World report on disability. WHO, 2011

5 Chatterji S, Byles J, Cutler D, Seeman T, Verdes E. Health, functioning, and disability in older adults - present status and future implications. Lancet 2015;385:563-75. doi:10.1016/S01406736(14)61462-8

6 Richards NC, Gouda HN, Durham J, Rampatige R, Rodney A, Whittaker M. Disability, noncommunicable disease and health information. Bull World Health Organ 2016;94:230-2. doi:10.2471/ BLT.15.156869
7 GBD 2017 Disease and Injury Incidence and Prevalence Collaborators. Global, regional, and national incidence, prevalence, and years lived with disability for 354 diseases and injuries for 195 countries and territories, 1990-2017: a systematic analysis for the Global Burden of Disease Study 2017. Lancet 2018;392:1789-858. doi:10.1016 S0140-6736(18)32279-7

8 GBD 2016 Disease and Injury Incidence and Prevalence Collaborators. Global, regional, and national incidence, prevalence, and years lived with disability for 328 diseases and injuries for 195 countries, 1990-2016: a systematic analysis for the Global Burden of Disease Study 2016. Lancet 2017;390:1211-59. doi:10.1016/S01406736(17)32154-2

9 Stein R. Trends in disability in early life. In: Field MJ, Jette AM, Martin L, eds. Workshop on disability in America: a new look. National Academies Press, 2006:143-56.

10 Houtrow AJ, Larson K, Olson LM, Newacheck PW, Halfon N. Changing trends of childhood disability, 2001-2011. Pediatrics 2014;134:530-8. doi:10.1542/peds.2014-0594

11 Bright T, Wallace S, Kuper H. A systematic review of access to rehabilitation for people with disabilities in low-and middle-income countries. Int J Environ Res Public Health 2018;15:2165. doi:10.3390/ ijerph15102165

12 Kamenov K, Mills JA, Chatterji S, Cieza A. Needs and unmet needs for rehabilitation services: a scoping review. Disabil Rehabil 2019;41:1227-37. doi:10.10 80/09638288.2017.1422036

13 World Health Organization. Early childhood development and disability: a discussion paper. WHO, 2012.

14 Unicef. State of the world's children 2013: children with disabilities. Unicef, 2013.

15 Olusanya BO, Wright SM, Nair MKC, et al, Global Research on Developmental Disabilities Collaborators (GRDDC). Global burden of childhood epilepsy, intellectual disability, and sensory impairments. Pediatrics 2020;146:e20192623. doi:10.1542/peds.2019-2623

16 Institute for Health Metrics and Evaluation. Global burden of disease results tool. IHME, 2019. http:// ghdx.healthdata.org/gbd-results-tool

17 The World Bank. Population ages 0-14 (\% of total). World Bank, 2019. https://data.worldbank.org/ indicator/SP.POP.0014.TO.ZS

18 United Nations General Assembly. Convention on the rights of the child. United Nations, 1989.

19 United Nations General Assembly. Convention on the rights of persons with disabilities. United Nations, 2006.

20 Devendra A, Makawa A, Kazembe PN, Calles NR, Kuper H. HIV and childhood disability: a casecontrolled study at a paediatric antiretroviral therapy centre in Lilongwe, Malawi. PLoS One 2013;8:e84024. doi:10.1371/journal. pone.0084024

21 Magnussen HJA. Childhood disability in rural Zambia: a qualitative study on the use of health care services. 2011

22 Adugna MB, Nabbouh F, Shehata S, Ghahari S. Barriers and facilitators to healthcare access for children with disabilities in low and middle income sub-Saharan African countries: a scoping review. BMC Health Serv Res 2020;20:15. doi:10.1186/ s12913-019-4822-6

23 Unicef. Early childhood intervention, special education and inclusion: focus on Belarus. Unicef, 2008.

24 Engle PL, Black MM, Behrman JR, et al, International Child Development Steering Group. Strategies to avoid the loss of developmental potential in more than 200 million children in the developing world. Lancet 2007;369:229-42. doi:10.1016/S01406736(07)60112-3

25 McConachie H, Huq S, Munir S, et al. Difficulties for mothers in using an early intervention service for 
children with cerebral palsy in Bangladesh. Child Care Health Dev 2001;27:1-12. doi:10.1046/ j.1365-2214.2001.00207.x

26 Montes G, Halterman JS, Magyar Cl. Access to and satisfaction with school and community health services for US children with ASD. Pediatrics 2009;124(suppl 4):S407-13. doi:10.1542/peds.2009-1255L

27 Spann SJ, Kohler FW, Soenksen D. Examining parents' involvement in and perceptions of special education services: an interview with families in a parent support group. Focus Autism Other Dev Disabl 2003;18:228-37. doi:10.1177/108835760 30180040401

28 Padmamohan J, Nair MK, Devi SR, Nair SR, Nair ML, Kumar GS. Utilization of rehabilitation services by rural households with disabled preschool children. Indian Pediatr 2009;46(suppl):s79-82.

29 World Health Organization. Assistive devices/ technologies: what WHO is doing. WHO, 2019.

30 Unicef. The state of the world's children 2013: children with disabilities. Unicef, 2013.

31 Tilahun D, Hanlon C, Fekadu A, Tekola B, Baheretibeb Y, Hoekstra RA. Stigma, explanatory models and unmet needs of caregivers of children with developmental disorders in a low-income African country: a cross-sectional facility-based survey. BMC Health Serv Res 2016;16:152. doi:10.1186/ s12913-016-1383-9

32 World Health Organization. The need to scale up rehabilitation. WHO, 2017.

33 Krug E, Cieza A. Strengthening health systems to provide rehabilitation services. Neuropsychol Rehabil 2019;29:672-4. doi:10.1080/09602011.2 017.1319391

34 Barr H. School closures particularly hard on children with disabilities. Human Rights Watch survey, 2020. https://www.hrw.org/ news/2020/06/15/school-closures-particularlyhard-children-disabilities

35 Orii A, Kamenov K, Dirac M, Davis A, Chadha S, Vos T. Global and regional needs, unmet needs and access to hearing aids. Int J Audiol 2020;59:166-72. doi:10. 1080/14992027.2020.1721577

36 Stucki G, Stier-Jarmer M, Grill E, Melvin J. Rationale and principles of early rehabilitation care after an acute injury or illness. Disabil Rehabil 2005;27:353 9. doi:10.1080/09638280400014105
37 Nguyen C, Lefèvre-Colau MM, Poiraudeau S, Rannou F. Rehabilitation (exercise and strength training) and osteoarthritis: A critical narrative review. Ann Phys Rehabil Med 2016;59:190-5. doi:10.1016/j. rehab.2016.02.010

38 World Health Organization. Risk reduction of cognitive decline and dementia. WHO, 2019.

39 Damiano DL. Rehabilitative therapies in cerebral palsy: the good, the not as good, and the possible. / Child Neurol 2009;24:1200-4 doi:10.1177/0883073809337919

Web supplements: Prevalence and years lived with disability attributed to different long term health conditions and impairments

Web supplements: Evidence on effectiveness of prevention, treatment, and rehabilitation interventions for long term health conditions

Cite this as: $B M / 2021 ; 372: n 9$

http://dx.doi.org/10.1136/bmj.n9 